\title{
Influence of demographic and metabolic variables on forearm blood flow and vascular conductance in individuals without overt heart disease
}

This article was published in the following Dove Press journal:

Vascular Health and Risk Management

29 May 2010

Number of times this article has been viewed

\author{
Thiago E Sartori' \\ Rafael AB Nunes' \\ Gisela T da Silva ${ }^{2}$ \\ Sandra C da Silva' \\ Maria UPB Rondon' \\ Carlos E Negrão' \\ Alfredo J Mansur' \\ 'Heart Institute (InCor), University \\ of São Paulo Medical School, São \\ Paulo, Brazil; ${ }^{2}$ Institute of Mathematics \\ and Statistics, University of São Paulo, \\ São Paulo, Brazil
}

Correspondence: Rafael Amorim Belo Nunes

Instituto do Coração (InCor) do Hospital das Clínicas da Faculdade de Medicina da Universidade de São Paulo, Av. Dr Eneas de Carvalho Aguiar, 44 São Paulo, Brazil CEP 05403-900

Tel +55 II 30695237

Fax +55 II 30822354

Email rafael.nunes@incor.usp.br
Purpose: Vascular reactivity is involved in the regulation of vascular function either in normal conditions or in the pathophysiology of cardiovascular diseases. We tested the hypothesis that vascular reactivity evaluated by forearm blood flow may vary according to demographic and metabolic variables in a cohort of individuals without any evidence of heart disease after clinical examination.

Subjects and methods: We studied 186 individuals (mean age 41.4 years, standard deviation 13.1 years; 95 (51\%) men and 91 (49\%) women. We investigated forearm blood flow and vascular conductance with venous occlusion plethysmography at baseline, during handgrip isometric exercise and during the recovery phase. Demographic and laboratory data were collected. Statistical analysis was performed with mixed linear models appropriate for repeated measurements.

Results: Mean forearm blood flow values in the different study conditions ranged between $1.7 \pm 0.47 \mathrm{~mL} \cdot \mathrm{min}^{-1} .100 \mathrm{~mL}^{-1}$ of tissue and $2.82 \pm 1.13 \mathrm{~mL} \cdot \mathrm{min}^{-1} .100 \mathrm{~mL}^{-1}$ of tissue. Forearm blood flow was higher in men than in women $(P<0.005)$ and increased as the heart rate increased during handgrip maneuver $(P<0.0001)$. Serum triglyceride levels were inversely related to forearm blood flow at baseline, during isometric exercise and recovery phase $(P=0.0209)$. Body mass index was inversely related to forearm vascular conductance at baseline, during isometric exercise and recovery phase $(P=0.0223)$.

Conclusion: Our findings suggest that forearm blood flow and vascular conductance as a surrogate of the vascular function may be influenced by gender, heart rate, serum triglyceride levels and body mass index in individuals without overt heart disease.

Keywords: forearm blood flow, triglycerides, body mass index, gender

\section{Introduction}

Venous occlusion plethysmography is a useful tool to estimate forearm blood flow for the evaluation of vascular function. ${ }^{1,2}$ In previous studies performed with this technique small samples sizes were enrolled which ranged between 30 and 66 participants. ${ }^{3-8}$ The findings of these studies have suggested that forearm blood flow may be influenced by clinical and metabolic variables such as gender, age, serum lipids, obesity and family history of myocardial infarction..$^{5-9}$

Abnormal vascular reactivity has been suggested to have a pivotal pathophysiological role in the pathogenesis of vascular disease, including clinical atherosclerosis and cardiovascular events. ${ }^{10}$ Knowledge of vascular reactivity in patients undergoing cardiological evaluation for a preventive purpose (check-up) relative to demographic and laboratory variables may be a question of everyday practice for preventive intervention and prompted us to perform this investigation. 
The aim of this study was to investigate forearm vascular reactivity evaluated by venous occlusion plethysmography to test the hypothesis that the forearm blood flow and the counterpart vascular conductance at rest and during handgrip maneuver (a known vasodilatory stimulus) may vary according to demographic and metabolic variables in individuals without overt heart disease.

\section{Methods}

\section{Study population}

We studied individuals of an ongoing cohort of patients that had undergone cardiological medical evaluation in a general outpatient clinic. Clinical evaluation included detailed medical examination, a 12-lead electrocardiogram, chest radiography, treadmill exercise test, color Doppler echocardiography and laboratory work-up.

Patients with evidence of heart or cerebrovascular disease, stage 2 or 3 hypertension (blood pressure $\geq 160 \times 100 \mathrm{mmHg}$ ), diabetes mellitus, cancer or other significant systemic diseases on medical treatment were excluded from this investigation.

Two hundred individuals were selected for the study protocol. From this group, 14 individuals were excluded due to: hypothyroidism (two participants); diabetes mellitus (two participants); technical limitations making forearm blood flow for analysis not feasible; and lack of clinical and laboratory data (ten participants). Thus, 186 participants remained in the study sample; mean age was 41.4 years (standard deviation [SD] 13.1 years), 95 (51\%) were men and 91 (49\%) women. Twenty-five participants (13.4\%) were smokers and $22(11.8 \%)$ had stage 1 hypertension.

\section{Forearm blood flow and vascular conductance}

Forearm blood flow was measured by venous occlusion plethysmography as previously described by Negrão and colleagues. ${ }^{11}$ The nondominant arm was elevated above heart level to ensure adequate venous drainage. A mercury-filled silastic tube attached to a low pressure transducer was placed around the forearm and connected to a plethysmograph (model EC6; Hokanson, Bellevue, WA, USA). Sphygmomanometer cuffs were placed around the wrist and upper arm. At 15 second intervals, the upper cuff was inflated above venous pressure for 7 to 8 seconds. Forearm blood flow (mL. $\mathrm{min}^{-1} .100 \mathrm{~mL}^{-1}$ of tissue) was determined on the basis of a minimum of four separate readings. Forearm blood conductance was computed as the ratio of forearm blood flow and mean arterial pressure. Forearm blood flow was measured at rest, during handgrip isometric exercise and the recovery phase.

\section{Blood pressure and heart rate}

Mean blood pressure was monitored non-invasively at rest with a finger plethysmograph device (Finapres 2300; Finapres, Amsterdam, Netherlands) on a beat-to-beat basis (AT/CODAS) at a frequency of $500 \mathrm{~Hz}$. During handgrip isometric exercise, mean blood pressure was monitored noninvasively and intermittently from an automatic and oscillometric cuff (DX 2710; Dixtal Medical, Wallingford, CT, USA) placed on the left ankle with cuff width adjusted to ankle circumference. Heart rate was monitored continuously through lead II of an electrocardiogram. The signal of electrocardiogram was recorded in frequency of $500 \mathrm{~Hz}$ and then analyzed in an AT/CODAS program.

\section{Handgrip exercise}

The handgrip isometric exercise was performed for 3 minutes at $30 \%$ of maximal voluntary contraction and followed by 3 minutes of recovery phase. Forearm blood flow, blood pressure, and heart rate were recorded every minute during handgrip exercise and recovery phase.

\section{Demographic and clinical variables}

Forearm blood flow and vascular conductance were evaluated relative to demographic variables (age, sex, body mass index [BMI], body surface area and waist circumference) and clinical variables: stage 1 hypertension (systolic blood pressure $\geq 140 \mathrm{mmHg}$ or diastolic blood pressure $\geq 90 \mathrm{mmHg}$ ) or not and smoking (active smoker or not).

\section{Laboratory variables}

Blood samples were collected after fasting for 12-hour (overnight) to determine: cholesterol and subfractions (low-density lipoprotein [LDL] and high-density lipoprotein [HDL] cholesterol); triglycerides; fasting blood glucose; hemoglobin level; platelet count; leukocytes count; serum creatinine; highly sensitive C-reactive protein (hs-CRP); and thyroid-stimulating hormone (TSH).

\section{Data analysis}

Descriptive and exploratory analyses of forearm blood flow were performed in different study conditions. Pearson correlation coefficients were computed to access the correlation among demographic and clinical variables. For the multivariate analysis, mixed linear models appropriate for repeated measurements for forearm blood flow and for forearm vascular conductance, as response variables, were developed to identify demographic and clinical variables that are statistically significant. Logarithmic transformation of the response variable was adopted due to the asymmetry 
of the distribution of the response variables. The selection of variables was done using both backward and forward procedures, with $P$ values $<0.05$. The selected models of the multivariate analysis were used to estimate forearm blood flow and forearm vascular conductance for different values of variables significantly associated with forearm blood flow.

\section{Ethics}

The study protocol was approved by the Ethics Committee on Human Research of the Hospital and all participants signed an informed consent.

\section{Results}

Demographic and laboratory characteristics of the study population are shown in Table 1.

Table I Demographic and laboratory characteristics of the study population

\begin{tabular}{|c|c|c|c|}
\hline Characteristics & Sex & Mean & $\begin{array}{l}\text { Standard } \\
\text { deviation }\end{array}$ \\
\hline \multirow[t]{2}{*}{ Age } & Women & 41.5 & 14.22 \\
\hline & Men & 41.3 & 11.98 \\
\hline \multirow[t]{2}{*}{ Weight (kg) } & Women & 67.2 & 13.14 \\
\hline & Men & 79.2 & 13.20 \\
\hline \multirow[t]{2}{*}{ Height (m) } & Women & 1.60 & 0.07 \\
\hline & Men & 1.70 & 0.07 \\
\hline \multirow[t]{2}{*}{ Body mass index $\left(\mathrm{kg} / \mathrm{m}^{2}\right)$} & Women & 26.8 & 4.91 \\
\hline & Men & 27.1 & 3.86 \\
\hline \multirow[t]{2}{*}{ Hemoglobin (g/dL) } & Women & 13.6 & 1.16 \\
\hline & Men & 15.5 & 0.88 \\
\hline \multirow[t]{2}{*}{ Creatinine (mg/dL) } & Women & 0.7 & 0.12 \\
\hline & Men & 1.0 & 0.16 \\
\hline \multirow[t]{2}{*}{ Total cholesterol (mg/dL) } & Women & 195.0 & 36.48 \\
\hline & Men & 196.3 & 40.02 \\
\hline \multirow[t]{2}{*}{ HDL-cholesterol (mg/dL) } & Women & 55.1 & 14.83 \\
\hline & Men & 46.7 & 10.40 \\
\hline \multirow[t]{2}{*}{ LDL-cholesterol (mg/dL) } & Women & 118.8 & 30.63 \\
\hline & Men & 121.7 & 33.46 \\
\hline \multirow[t]{2}{*}{ Triglycerides (mg/dL) } & Women & 106.0 & 55.35 \\
\hline & Men & |45.| & 84.41 \\
\hline \multirow[t]{2}{*}{ Body surface area $\left(m^{2}\right)$} & Women & 1.7 & 0.50 \\
\hline & Men & 2.5 & 5.57 \\
\hline \multirow[t]{2}{*}{ Waist circumference $(\mathrm{cm})$} & Women & 87.0 & 16.09 \\
\hline & Men & 91.9 & 9.77 \\
\hline \multirow[t]{2}{*}{ Leukocytes (count/mL) } & Women & 6863.5 & 1748.17 \\
\hline & Men & 6903.8 & 1919.43 \\
\hline \multirow[t]{2}{*}{ Fasting glucose (mg/dL) } & Women & 91.3 & 8.56 \\
\hline & Men & 95.0 & 8.45 \\
\hline \multirow[t]{2}{*}{$\mathrm{TSH}(\mu \mathrm{Ul} / \mathrm{mL})$} & Women & 1.9 & 1.54 \\
\hline & Men & 2.4 & 1.55 \\
\hline \multirow[t]{2}{*}{ Platelets $\left(\times 10^{3} / \mathrm{mm}^{3}\right)$} & Women & 263.2 & 85.15 \\
\hline & Men & 251.6 & 49.07 \\
\hline \multirow[t]{2}{*}{ hs-CRP (mg/L) } & Women & 1.9 & 3.17 \\
\hline & Men & 1.0 & 1.94 \\
\hline
\end{tabular}

Abbreviations: HDL, high-density lipoprotein; LDL, low-density lipoprotein; TSH thyroid-stimulating hormone; hs-CRP, highly sensitive C-reactive protein.

\section{Forearm blood flow}

Forearm blood flow distribution for the whole study sample in each condition of the experiment (baseline, exercise and recovery) revealed a predominant left lateral distribution (Figure 1). Forearm blood flow values in each condition are presented in Table 2.

For the multivariate analysis, the final mixed linear model of the logarithm of forearm blood flow revealed that gender, heart rate during handgrip exercise and serum triglycerides were statistically significant variables, after adjustment for the covariates in the model (Table 3). The variables not statistically significant in the model for the forearm blood flow logarithm ( $P$ value $>0.05)$ were: blood pressure during handgrip isometric exercise; smoking; stage 1 hypertension; age; abdominal circumference; body surface area; hemoglobin; leukocyte concentration; fasting glucose; total cholesterol; HDL-cholesterol; LDL-cholesterol; TSH; hsCRP; and BMI.

Male patients presented, on average, with a value of forearm blood flow greater than women (Table 3 and Figure 2). Moreover, there was an inverse relationship between the forearm blood flow and serum triglyceride levels; ie, an increase in the level of triglycerides led to a decrease in the expected value of forearm blood flow, at rest and during handgrip maneuvers (Table 3 ). Regarding heart rate and the forearm blood flow, a direct relationship was observed; ie, an increase in heart rate during handgrip isometric exercise led to an increase in forearm blood flow (Table 3). Heart rate values at baseline, during handgrip exercise and recovery phase are shown in Table 5.

\section{Forearm vascular conductance}

The final model for the logarithm of the forearm vascular conductance takes into account the BMI as a factor that may affect the expected value of the forearm vascular conductance (Table 4). BMI demonstrated a negative relationship with the expected value of the forearm vascular conductance at rest and during handgrip maneuver, ie, an increase in BMI led to a decrease in the expected value of the forearm vascular conductance (Figure 3).

The variables excluded from the final model for the vascular conductance logarithm $(P$ value $>0.05)$ were: stage 1 hypertension, smoking; gender; age; heart rate and blood pressure during handgrip isometric exercise; abdominal circumference; body surface area; hemoglobin; leukocyte concentration; fasting glucose; total cholesterol; HDL-cholesterol; LDL-cholesterol; serum triglycerides; hsCRP; and TSH.

\section{Discussion}

We were able to ascertain during this study, with a sample of individuals with no evidence of significant heart disease 


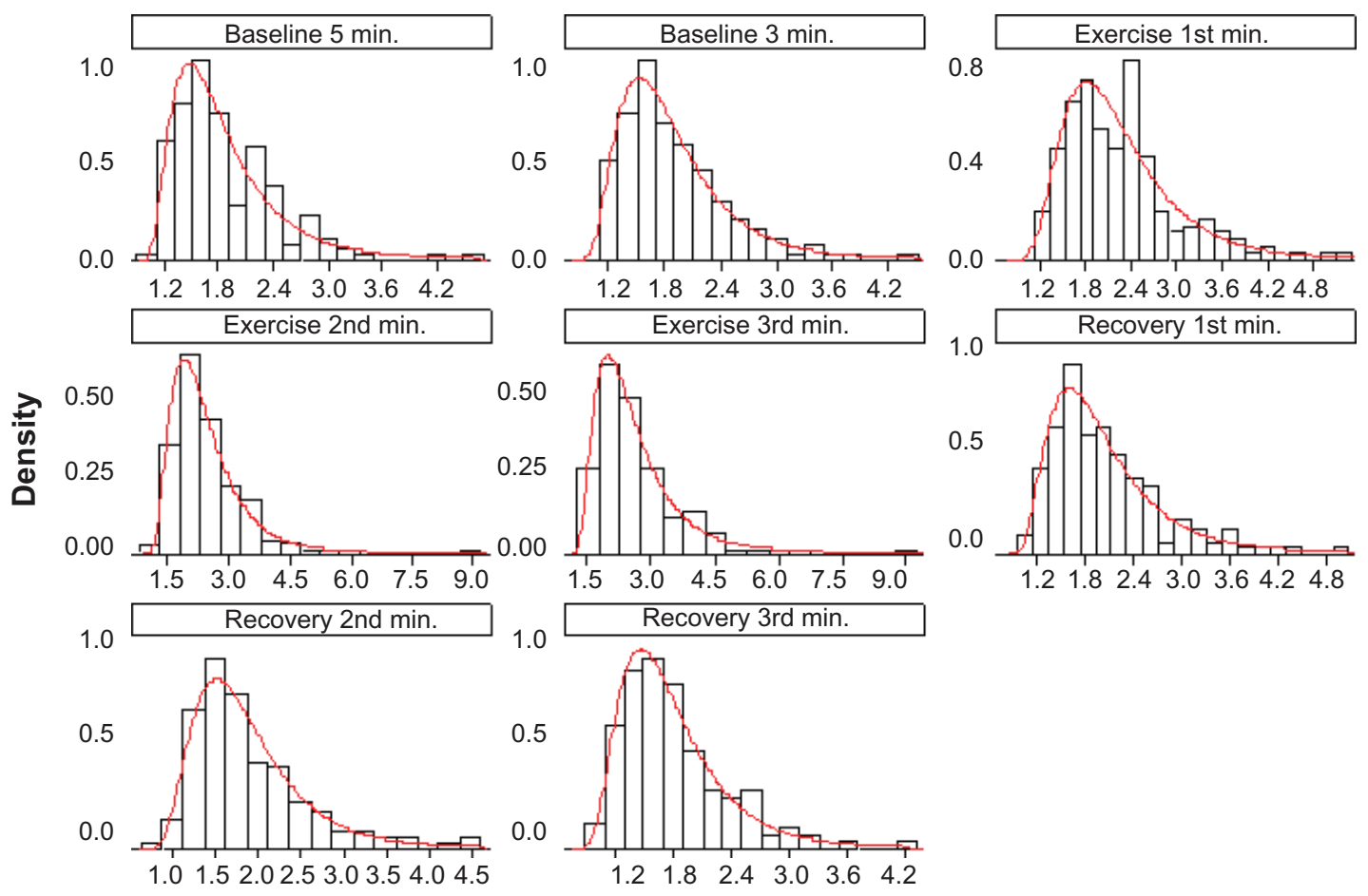

Figure I Forearm blood flow (mL. $\mathrm{min}^{-1} .100 \mathrm{~mL}^{-1}$ of tissue) with lognormal adjustment.

Notes: Each graph represents the study condition - baseline 5 minutes and 3 minutes before handgrip, Ist, 2nd and 3rd minutes of hand grip, and Ist, 2nd and 3rd minutes of recovery.

and that underwent cardiological evaluation for preventive purposes; who were submitted to venous occlusion plethysmography at rest and during handgrip exercise, to evaluate the relationship between forearm blood flow and clinical and laboratory variables.

Table 2 Forearm blood flow before handgrip, during handgrip, and during recovery

\begin{tabular}{llll}
\hline $\begin{array}{l}\text { Forearm blood flow } \\
\text { (mL.min }{ }^{-1} .100 \mathrm{~mL}^{-1} \text { of tissue) }\end{array}$ & Sex & Mean & $\begin{array}{l}\text { Standard } \\
\text { deviation }\end{array}$ \\
\hline Baseline 5 minutes & Women & 1.79 & 0.54 \\
& Men & 1.92 & 0.60 \\
Baseline 3 minutes & Women & 1.78 & 0.53 \\
& Men & 1.99 & 0.59 \\
Handgrip Ist minute & Women & 2.08 & 0.67 \\
& Men & 2.39 & 0.79 \\
Handgrip 2nd minute & Women & 2.21 & 0.70 \\
& Men & 2.62 & 1.07 \\
Handgrip 3rd minute & Women & 2.36 & 0.79 \\
& Men & 2.82 & 1.13 \\
Recovery Ist minute & Women & 1.86 & 0.61 \\
& Men & 2.14 & 0.75 \\
Recovery 2nd minute & Women & 1.74 & 0.57 \\
& Men & 2.02 & 0.71 \\
Recovery 3rd minute & Women & 1.70 & 0.47 \\
& Men & 1.88 & 0.58 \\
\hline
\end{tabular}

Notes: Forearm blood flow (mL.min $1.100 \mathrm{~mL}^{-1}$ of tissue) at baseline 5 minutes and 3 minutes before hand grip, Ist, 2nd and 3rd minutes of hand grip, and Ist, 2nd and 3rd minutes of recovery.
The distribution of the forearm blood flow seems to have an asymmetric distribution. The distribution of the values of forearm blood flow followed a similar pattern of distribution at baseline, during exercise and in the recovery phase after the handgrip maneuver. This finding may suggest that the ability of increasing forearm blood flow during handgrip exercise follows the pattern of baseline values and that this pattern does not change during exercise. This finding was also apparent on the estimated forearm blood flow values depicted in Figure 3.

Table 3 Estimates of the final model for the logarithm of forearm blood flow

\begin{tabular}{llll}
\hline $\begin{array}{l}\text { Forearm blood flow } \\
\left(\mathbf{m L} \text {.min-1.100 } \mathrm{mL}^{-1}\right. \\
\text { of tissue })\end{array}$ & Estimate & $\begin{array}{l}\text { Standard } \\
\text { error }\end{array}$ & P-value \\
\hline Intercept & $0.305 \mathrm{I}$ & 0.0676 & $<0.000$ I \\
Exercise Ist minute & 0.1495 & 0.0114 & $<0.000$ I \\
Exercise 2nd minute & 0.2084 & 0.0123 & $<0.000$ I \\
Exercise 3rd minute & 0.2696 & 0.0128 & $<0.000$ I \\
Recovery Ist minute & 0.0598 & 0.0109 & $<0.000$ I \\
Recovery 3rd minute & -0.0277 & 0.0117 & 0.0184 \\
Male & 0.1491 & 0.0423 & 0.0005 \\
Heart rate & 0.0045 & 0.0008 & $<0.000$ I \\
Triglycerides & -0.0007 & 0.0003 & 0.0209 \\
\hline
\end{tabular}



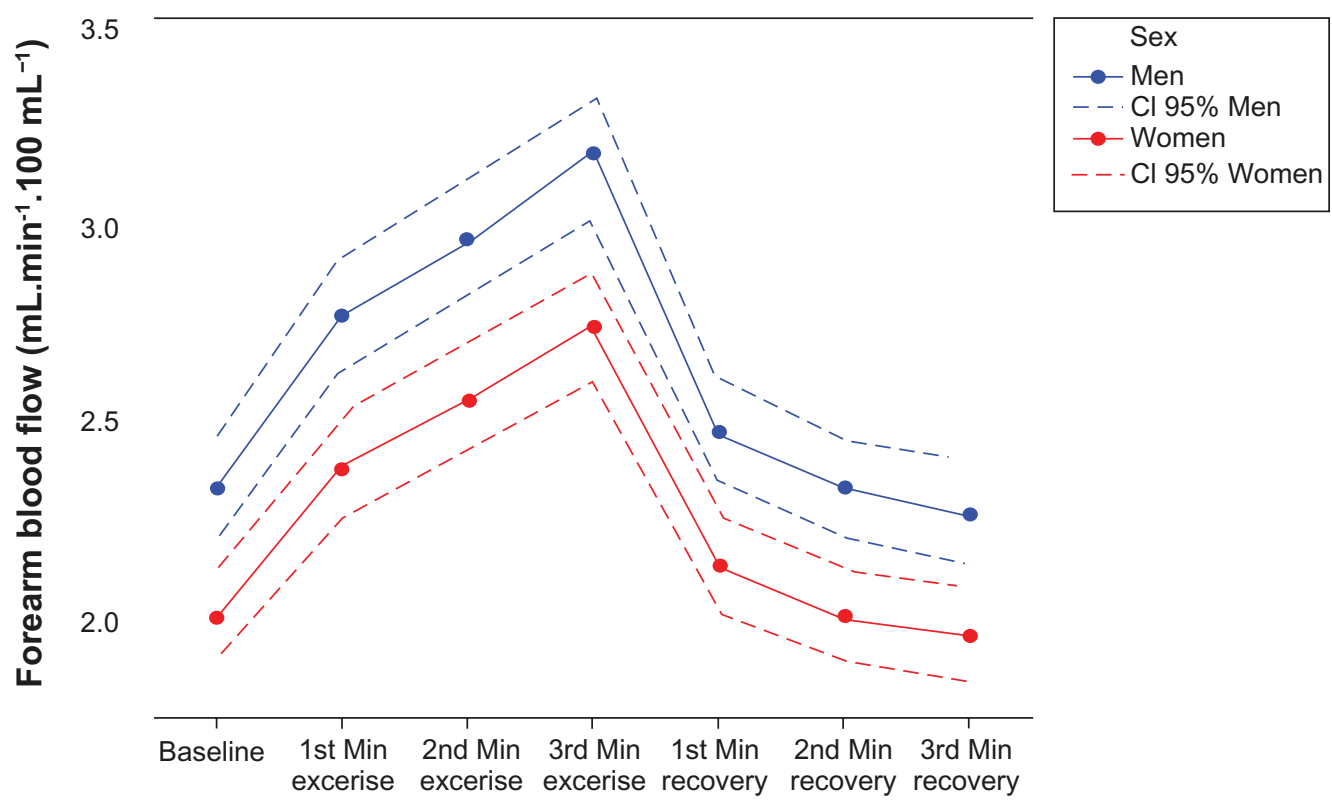

Figure 2 Estimates of values of forearm blood flow before handgrip, during handgrip, and during recovery.

Notes: Estimates of values of forearm blood flow ( $\mathrm{mL}_{\mathrm{min}} \mathrm{m}^{-1} .100 \mathrm{~mL}^{-1}$ of tissue) for the men and the women at baseline (heart rate 65 beats per minute), Ist (heart rate 70 beats per minute), 2nd (heart rate 72 beats per minute), and 3rd (heart rate 74 beats per minute), minutes of handgrip, and I st (heart rate 65 beats per minute), 2 nd (heart rate 65 beats per minute), and 3rd (heart rate 65 beats per minute), minutes of recovery. Estimates were done for triglycerides $122 \mathrm{mg} / \mathrm{dL}$.

Abbreviation: $\mathrm{Cl}$, confidence interval.

Previous studies focused on forearm blood flow differences between men and women were controversial. Two small studies including 31 and 38 subjects respectively found no significant difference in forearm blood flow response between men and women at the end of exercise sustained until fatigue. ${ }^{3,4}$ In another related study, forearm blood flow response was higher in men at the end of the 4-minute handgrip maneuver, but not at fatigue time. ${ }^{12}$ In our study, the 3-minute handgrip maneuver was associated with higher forearm blood flow values in men than in women, suggesting that forearm blood flow during the first minutes of isometric exercise is higher in men than women.

We observed a positive association between the increase in the heart rate during isometric exercise and the forearm blood flow. Heart rate augmentation during exercise increases cardiac output and blood perfusion to peripheral muscles. At the same time, the balance between sympathetic and parasympathetic

Table 4 Estimates of the final model for the logarithm of conductance

\begin{tabular}{llll}
\hline & Estimate & $\begin{array}{l}\text { Standard } \\
\text { error }\end{array}$ & P-value \\
\hline Intercept & 0.9385 & 0.1339 & $<0.0001$ \\
Exercise Ist minute & $0.098 \mathrm{I}$ & 0.0124 & $<0.000 \mathrm{I}$ \\
Exercise 2nd minute & 0.1145 & 0.0124 & $<0.000 \mathrm{I}$ \\
Exercise 3rd minute & 0.1486 & 0.0124 & $<0.000 \mathrm{I}$ \\
Recovery Ist minute & 0.0607 & 0.0125 & $<0.000 \mathrm{I}$ \\
Body mass index & -0.0113 & 0.0049 & 0.0223 \\
\hline
\end{tabular}

tonus during exercise may influence muscular vasodilatation and heart rate through adrenergic receptor stimulus. ${ }^{13}$

An interesting finding of this study was the inverse relationship between the forearm blood flow and serum triglyceride levels. Although high triglyceride levels are commonly associated with other clinical and metabolic conditions, we found no association between forearm blood flow and other

Table 5 Heart rate before handgrip, during handgrip, and during recovery

\begin{tabular}{llll}
\hline & Sex & Mean & $\begin{array}{l}\text { Standard } \\
\text { deviation }\end{array}$ \\
\hline Baseline 5 minutes & Women & 67.9 & 10.5 \\
& Men & 64.7 & 9.6 \\
Baseline 3 minutes & Women & 66.4 & 9.4 \\
& Men & 63.9 & 8.5 \\
Handgrip Ist minute & Women & 69.4 & 10.1 \\
& Men & 69.9 & 9.0 \\
Handgrip 2nd minute & Women & 72.4 & 11.0 \\
& Men & 72.6 & 9.4 \\
Handgrip 3rd minute & Women & 73.6 & 10.9 \\
& Men & 74.1 & 11.1 \\
Recovery Ist minute & Women & 66.7 & 10.0 \\
& Men & 63.8 & 9.3 \\
Recovery 2nd minute & Women & 66.5 & 9.6 \\
& Men & 63.6 & 9.2 \\
Recovery 3rd minute & Women & 66.4 & 9.7 \\
& Men & 63.6 & 9.3 \\
\hline
\end{tabular}

Notes: Heart rate (beats per minute) at baseline 5 minutes and 3 minutes before handgrip, Ist, 2nd and 3rd minutes of handgrip, and Ist, 2nd and 3rd minutes of recovery. 


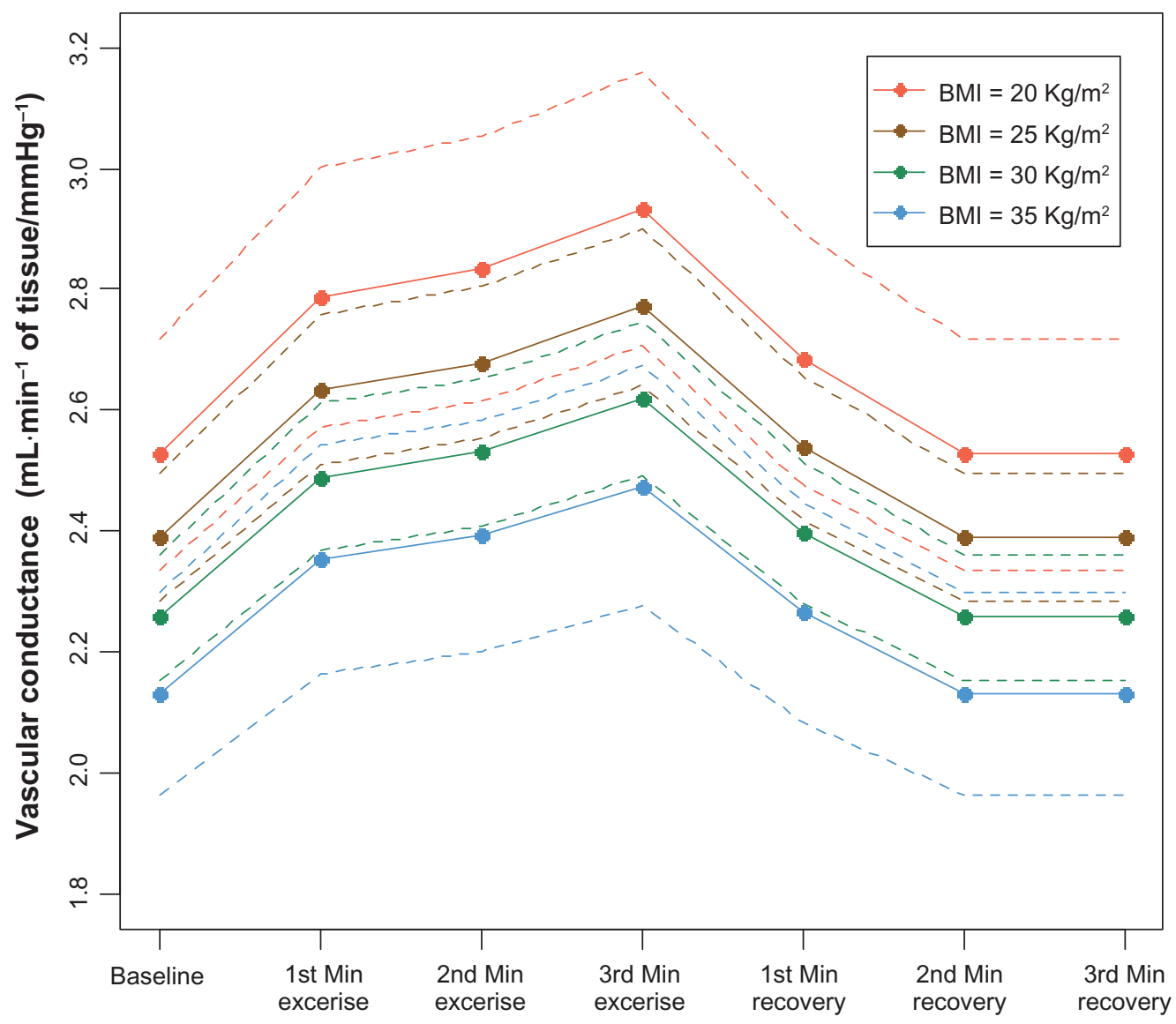

Figure 3 Estimates of vascular conductance values relative to body mass index before handgrip, during handgrip, and during recovery.

Notes: Estimates of vascular conductance values $\left(\mathrm{mL} \cdot \mathrm{min}^{-1} \cdot 100 \mathrm{~mL}^{-1}\right.$ of tissue $\left./ \mathrm{mmHg}^{-1}\right)$ relative to body mass index at baseline, Ist, $2 \mathrm{nd}$ and $3 \mathrm{rd}$ minutes of handgrip, and Ist, 2nd and 3rd minutes of recovery.

Abbreviation: BMI, body mass index.

variables related to metabolic syndrome such as body weight, arterial blood pressure, abdominal circumference and serum cholesterol levels, suggesting that serum triglycerides may be an independent factor for the forearm vascular response. Our finding may be considered consistent with a previous study that reported an attenuated forearm blood flow response to serotonin in eight patients with chronic hypertriglyceridemia when compared with 10 age-matched control subjects. ${ }^{14}$ In another related study, the treatment with fenofibrate in 11 hypertriglyceridemic patients improved forearm blood flow response to acetylcholine (endothelium-dependent vasodilatation) and to sodium nitroprusside (endothelium-independent vasodilatation). ${ }^{15}$ The role of triglycerides in cardiovascular disease has been debated and current evidence is conflicting. ${ }^{16,17}$ Future studies are necessary to clarify the influence of triglycerides and its management on vascular function.

Forearm conductance at rest and during the handgrip maneuver was inversely associated to BMI. A previous study demonstrated that obese children had lower forearm conductance than lean children at rest and during a handgrip maneuver, and this difference was abolished after intervention therapy with diet and physical training..$^{18}$ Our finding supports the concept that the increase in BMI may be associated with impaired vascular function in individuals without overt cardiovascular disease.

We recognize several limitations in our study. We were not able to evaluate some important variables such as the use of oral contraceptives and the physical status of the participants. The transversal study design limited us to establish a causal relationship between the studied variables and the forearm blood flow response. The small number of smokers and stage 1 hypertensive participants enrolled may have influenced the final models for the forearm blood flow and vascular conductance logarithms.

\section{Conclusions}

In a sample of individuals, without overt heart disease, that had undergone cardiological evaluation for preventive purposes, forearm blood flow at rest, during isometric exercise and during the recovery phase was higher in men 
than in women, increased with the increase in heart rate and was inversely associated with serum triglycerides. Vascular conductance was inversely associated with BMI.

Our findings suggest that forearm blood flow and vascular conductance as a surrogate of vascular function may be influenced by gender, heart rate, triglyceridemia and BMI in individuals without overt heart disease.

\section{Disclosures}

The authors report no conflict of interest relevant to this study.

\section{References}

1. Middlekauff HR, Nguyen AH, Negrao CE, et al. Impact of acute mental stress on sympathetic nerve activity and regional blood flow in advanced heart failure: implications for 'triggering' adverse cardiac events. Circulation. 1997;96:1835-1842.

2. Wilkinson IB, Webb DJ. Venous occlusion plethysmography in research: methodology and clinical applications. J Clin Pharmacol. 2001;52:631-646.

3. Thompson BC, Fadin T, Pincivero DM, Scheuermann BW. Forearm blood flow responses to fatiguing isometric contractions in women and men. Am J Physiol Heart Circ Physiol. 2007;293:H805-H812.

4. Gonzales JU, Thompson BC, Thistlethwaite JR, Harper AJ, Scheuermann BW. Forearm blood flow follows work rate during submaximal dynamic forearm exercise independent of sex. J Appl Physiol. 2007;103: 1950-1957.

5. Kneale BJ, Chowienczyk PJ, Brett SE, Coltart DJ, Ritter JM. Gender differences in sensitivity to adrenergic agonists of forearm resistance vasculature. J Am Coll Cardiol. 2000;36:1233-1238.

6. Sarabi M, Millgard J, Lind L. Effects of age, gender and metabolic factors on endothelium dependent vasodilatation: a population-based study. J Intern Med. 1999;246:265-274.
7. Sarabi M, Vessby B, Millgard J, Lind L. Endothelium-dependent vasodilatation is related to the fatty acid composition of serum lipids in healthy subjects. Atherosclerosis. 2001;156:349-355.

8. Trombetta IC, Batalha LT, Rondon MUPB, et al. Weight loss improves neurovascular and muscle metaboreflex control in obesity. Am J Physiol Heart Circu Physiol. 2003;285:H974-H982.

9. Lind L, Sarabi M, Millgard J, Kahan T. Endothelium-dependent vasodilatation is impaired in apparently healthy subjects with a family history of myocardial infarction. J Cardiovasc Risk. 2002;9:53-57.

10. Lerman A, Zeither AM. Endothelial Function - Cardiac Events. Circulation. 2005;111:363-368.

11. Negrão CE, Hamilton E, Foronow G, Hage A, Moriguchi JD, Middlekauff HR. Impaired endothelium-mediated vasodilation is not the principal cause of blood vasoconstriction in heart failure. Am J Physiol Heart Circ Physiol. 2000;278:H168-H174.

12. Hunter SK, Schletty JM, Schlachter KM, Griffith EE, Polichnowski AJ, $\mathrm{Ng}$ AV. Active hyperemia and vascular conductance differ between men and women for isometric fatiguing contraction. $J$ Appl Physiol. 2006;101:140-150.

13. Sanders JS, Mark AL, Ferguson DW. Evidence for cholinergically mediated vasodilatation at the beginning of isometric exercise in humans. Circulation. 1989;79(4):815-824.

14. de Man FH, Weverling-Rijnsburger AW, van der Laarse A, Smelt AH, Jukema JW, Bluw GJ. Not acute but chronic hypertriglyceridemia is associated with impaired endothelium-dependent vasodilatation. Arterioscler Thromb Vasc Biol. 2000;20:744-750.

15. Capell WH, DeSouza CA, Poirier P, et al. Short-term triglycerides lowering with fenofibrate improves vasodilator function in subjects with hypertriglyceridemia. Arterioscler Thromb Vasc Biol. 2003;23:307-313.

16. Gandotra P, Miller M. The role of triglycerides in cardiovascular risk. Current Cardiol Rep. 2008;10:505-511.

17. Di Angelantonio E, Sarwar N, Perry P, et al. Major lipids, apolipoproteins, and risk of vascular disease. JAMA. 2009;302(18):1993-2000.

18. Ribeiro MM, Silva AG, Santos NS, et al. Diet and exercise training restore blood pressure and vasodilatory responses during physiological maneuvers in obese children. Circulation. 2005;111:1915-1923.
Vascular Health and Risk Management

\section{Publish your work in this journal}

Vascular Health and Risk Management is an international, peerreviewed journal of therapeutics and risk management, focusing on concise rapid reporting of clinical studies on the processes involved in the maintenance of vascular health; the monitoring, prevention and treatment of vascular disease and its sequelae; and the involvement of

\section{Dovepress}

metabolic disorders, particularly diabetes. This journal is indexed on PubMed Central and MedLine. The manuscript management system is completely online and includes a very quick and fair peer-review system, which is all easy to use. Visit http://www.dovepress.com/ testimonials.php to read real quotes from published authors. 